\title{
How macroeconomic shocks impact employment: comparison of Gujarat with states in Western India
}

\author{
Jeemol Unni ${ }^{1}$ D $\cdot$ Pritha Dev $^{2}$ \\ Accepted: 25 October 2020 / Published online: 22 February 2021 \\ (c) Institute for Social and Economic Change 2021
}

\begin{abstract}
In this paper, we discuss the impact of the macroeconomic shock of demonetisation on employment in the five Western states of Gujarat, Maharashtra, Rajasthan, Chhattisgarh and Madhya Pradesh. We analyse the impact of the macroeconomic shocks on workforce participation rates (WPR) in the states. We do this separately for overall and separately for men and women. We use the Center for Monitoring the Indian Economy's (CMIE) Consumer Pyramids Household Survey (CPHS), which allows us to look at monthly workforce participation rates of men and women in the age group of 15-64 years for the period from January 2014 to December 2019. Overall, the trendline structural break figures of the shock of demonetisation were corroborated by the regression results. Demonetisation had a significant negative impact on WPR of all workers in Maharashtra, Madhya Pradesh and Chhattisgarh and on male WPR in Maharashtra, Madhya Pradesh and Rajasthan. A significant negative impact of demonetisation on women's WPR was corroborated by the regression equations for Chhattisgarh and Madhya Pradesh. Employment for all, males and females in Gujarat was not significantly affected by the shock of demonetisation. It appeared that workers in Gujarat were better able to negotiate the shock.
\end{abstract}

Keywords Gender · Work participation · Employment · Macroeconomic shock · Labour force participation $\cdot$ Gujarat

\section{Introduction}

The Western state of Gujarat has been lauded for having a dynamic model of growth 'Gujarat Model of Development' (Sood 2012). However, this has also been contested by Sood himself and other authors (Hirway et al. 2014). In an earlier paper, we had noted that during the period of rapid economic growth till 2010-2011, employment remained almost stagnant. Informalisation of labour and wage rate increased only marginally. The benefits

Jeemol Unni

jeemol@gmail.com

Pritha Dev

pritha@iima.ac.in

1 Ahmedabad University, Ahmedabad, India

2 Indian Institute of Management, Ahmedabad, India 
of the rapid growth were not passed on to labour in the state, while the neighbouring state of Maharashtra created jobs in the formal sector and larger registered enterprises (Unni and Naik 2014, pp. 270-299).

The world economy, India and the state of Gujarat are currently reeling under the shock of the pandemic and its aftermath. Some of the sheen of the Gujarat model has been wiped off as the state is found to have a fast rate of growth of persons affected by the virus and worse still, high morbidity. This points to a weak health infrastructure in spite of the rapid economic growth in the state. Unfortunately the Indian economy had already been subjected to two macroeconomics shocks, demonetisation in November 2016 and implementation of the Goods and Services Tax (GST) in July 2017. The shock of the strict lockdown for two months only added to the economic problems facing the country.

In this paper, we discuss the impact of the macroeconomic shock of demonetisation on employment in the five Western states of Gujarat, Maharashtra, Rajasthan, Chhattisgarh and Madhya Pradesh. We analyse the impact of the macroeconomic shocks on workforce participation rates (WPRs) in the states. We do this separately for overall and separately for men and women. We use the Center for Monitoring the Indian Economy's (CMIE) Consumer Pyramids Household Survey (CPHS) which allows us to look at monthly workforce participation rates of men and women in the age group of 15-64 years for the period from January 2014 to December 2019.

\section{Review of literature}

There is a vast literature on the impact of economic shocks on women's work in East Asia, Indonesia, low- and middle-income countries. Lim (2000) found that in Philippines during the crisis unemployment rate fell more among men than that of women as women took up activities in personal services and trade and worked longer hours as a coping mechanism. Similarly, increase in participation in self-employed work to tide over the crisis was noted in Indonesia (Smith et al. 2002). Kim and Voos (2007) found that more women than men dropped out of the workforce in South Korea during the crisis of 1997 due to the discouraged worker effect. This happens when women perceive a lack of demand for the kind of work they would like to do or can do due to the level of education and other factors.

The macroeconomic shock of demonetisation and its impact on India's economy has been considered by scholars. On 8 November 2016, the Prime Minister declared demonetisation of current Rs. 500 and Rs. 1000 notes with an immediate effect. India has been a primarily cash-based economy, and this move brought large sectors of the economy to a grinding halt. These included most transactions in agriculture and small and micro-enterprises in the informal sector. In some sense, this decision is very similar to what we witnessed from March 25th when the Prime Minister declared an immediate and complete lockdown of the economy to prevent the spread of the coronavirus. The latter event was an even larger macroeconomic shock to the economy as it disrupted production and supply chains completely for a period of two months. In this paper, we analyse the impact of the first macroeconomic shock of demonetisation and the second shock of implementation of GST.

The impact on the shock of demonetisation on the informal small and medium enterprises (SME) was maximum due to the fact that they were mainly 'unbanked' and dependent largely on cash (IDF 2017). In a survey of 48 districts in 9 states, the authors found that among the SMEs where workers were mainly migrants, production activity declined 
by 74 percent, labour employed by 71 percent and wages paid by 39 percent compared to the same period in the previous year. Another impact similar to the recent COVID 19 lockdown was that reverse migration from cities to villages was higher by 72 percent and demand for MGNREGA work rose by 43 percent compared to the previous year (IDF 2017).

Similar results were found in a survey done in rural Tamil Nadu of 2692 individuals (Guerin et.al. 2017). Among persons who worked in the past year, one-third declared that they worked less after demonetisation and 6 percent reported that they got no work at all in their primary occupation. About 19 percent had a secondary occupation, of whom onethird declared this economic activity was stopped. Gender difference noted was that while 62 percent of men worked less in the primary occupation, 72 percent of women had to stop work completely due to demonetisation (Guerin et. al. 2017).

While these studies discuss the immediate negative impact of demonetisation on employment, other studies found some positive results in the year and a half after the event. Chanda (2019) found that the districts that had higher growth of bank deposit in the quarter after demonetisation experienced a decline in nightlight intensity during the same period, but showed sharp increase through all of 2017 and early 2018. And these tended to be the poorer districts. Further, poorer households also saw an increase in household expenditure and incomes compared to the rich in 2017 and early 2018. He concluded that in the medium term, demonetisation had a redistribution effect and may also have aided money laundering.

Chodorow-Reich et. al. (2020) used a macro-model to show district-level exposure to demonetisation using nightlight data. Using elasticity to impute aggregate output reduction, they showed that demonetisation had an immediate negative impact on nightlight growth, credit growth and employment. But these effects were temporary and disappeared in the first quarter of 2017.

Karmakar and Narayanan (2019) studied the impact of demonetisation on expenditure of households with bank accounts and those without bank accounts. The households without bank accounts showed a major reduction in expenditure immediately after demonetisation, but the recovery was quick with expenditures rising soon after. He, however, attributes this to consumption smoothing through borrowing.

Our results highlight that macro-shocks have a gendered impact and are likely to have a harsher impact on women's participation in the workforce. Women's workforce participation is broadly studied in terms of the 'income effect' and the 'substitution effect'. The 'income effect' is when the household income rises and women tend to withdraw from the labour market. The 'income effect' (Mehrotra and Sinha 2017) is interpreted in India to mean a reduction in the prestige of the household when women work, or worse, a 'stigma' attached to women's work (Gupta et al. 2020). The 'substitution effect' implies that the opportunity cost of staying at home for the educated women who earn higher incomes is large, and hence, they would prefer to work. The final result depends on whether in a society, the income or substitution effect is stronger. Another view of women's workforce participation is that women withdraw from the workforce, reflected in a decline, due to a 'discouraged worker effect' (Unni 2020). This happens when the women perceive a lack of demand for the kind of work they would like to do or can do due to level of education and other factors.

In India, the National Sample Survey Organisation (NSSO) and Employment and Unemployment Survey (EUS) data are most commonly used to analyse changes in employment. The EUS was a quinquennial survey available once in five years. This system was changed to a yearly survey of employment under the Periodic Labour Force Survey 
(PLFS). Most researchers agreed that there was a decline in employment between NSO, Employment Unemployment Survey, 2011-2012 and PLFS 2017-2018, particularly sharply among women in rural and urban areas (Unni 2020). Few reports on the results were varied, with some claiming that there was a loss of employment to the tune of 15.5 million (Himanshu 2019) and others claiming the loss was around 6.1 million (Kannan and Raveendran 2019a). Kannan and Raveendran (2019b) argued that India was in a state of 'jobless' growth, where there is no growth in employment when the output growth is positive. But the country had moved to a state of 'job-loss' growth, where there was a net decline in the absolute number of workers even with positive output growth. Overall, the employment situation in India was grim even before the COVID-19 shock, partly due to the macro-shocks of demonetisation and implementation of GST.

\section{Data}

In India, the National Sample Survey Organisation (NSSO) and Employment and Unemployment Survey (EUS) data are most commonly used to analyse changes in employment. The EUS was a quinquennial survey available once in five years. This system was changed to a yearly survey of employment under the Periodic Labour Force Survey (PLFS). They provide relatively good estimates of employment given its large sample size in rural and urban areas. However, as of now data from these sources are available only every five years.

In this paper, we use the CMIE's CPHS data as it has the major advantage of providing employment data for every month of the year on a continuous basis. We are able to derive a time-series data set for 60 months from January 2014 to December 2019. CPHS sample coverage is lower than that of the NSO data. The limitation of the CPHS data is that while male workforce participation rates (WPR) for prime age groups are more or less similar to the NSO data, WPR for women is lower in the CPHS data. CPHS women's WPR in urban areas was closer to the NSO estimates, while the rural WPR was much lower. In this paper, we use the overall, rural and urban, employment data from the CMIE, CPHS.

We use information contained in the CPHS People of India database to get demographic details regarding the household and the members. This database gives us information on occupational category. We categorise a person as being part of the workforce only if their stated occupation is anything other than 'Retired/Aged', 'NonSchooling Child', 'Home Maker', 'Student', 'Unoccupied' and if they are in the age range of 15-64.

Our dataset includes data for all members of all sample households in the age range of 15-64 for the period from January 2014 to December 2019. ${ }^{1}$ From this member-level data for 70 months, we first constructed the workforce participation (WPR) rate at the overall level and separately for men and women. From this, we are able to see the trends in WPR. Workforce Participation Rate

We first construct the overall workforce participation for the entire working age population separately by gender. We calculate the monthly participation rate as follows:

$$
\mathrm{WPR}_{m}=\frac{\text { Workers in month } \mathrm{m} \text { in age group15 }-64}{\text { Total population in month } \mathrm{m} \text { in age group15 }-64}
$$

\footnotetext{
1 We consider the median age for the entire period for each person to remove variability shown in reported ages for the same person over time.
} 
Similarly, for the two genders we calculate their participation rates as:

$$
\begin{aligned}
F \mathrm{WPR}_{m} & =\frac{\text { Female workers in month } \mathrm{m} \text { in age group15 }-64}{\text { Total female population in month } \mathrm{m} \text { in age group15 -64 }} \\
\mathrm{MWPR}_{m} & =\frac{\text { Male workers in month } \mathrm{m} \text { in age group15 }-64}{\text { Total male population in month } \mathrm{m} \text { in age group15 }-64}
\end{aligned}
$$

\section{Trendline graphs}

In order to analyse the impact of the macro-shock of demonetisation on employment, we look for whether there is a structural break with demonetisation, indicated by a vertical line for November 2016. In the graphs below we fit linear trends before and after the demonetisation event using the month-wise data on WPR for the 70 months from January 2014 to December 2019. This is done for all the five Western states.

We can see that just graphically there is evidence of change in trends following demonetisation. For overall population in four of the five states, except Gujarat, the trend line of WPR was rising before demonetisation and uniformly becomes sharply negatively sloped after the event. In case of male and female WPR, we note some differences for states. In Gujarat, the overall and female WPR was rising before demonetisation and continued to rise after the event. Male WPR in Gujarat, however, showed a downward trend before and after the shock. For male and female workers in Madhya Pradesh and Chhattisgarh, the trend line of female WPR showed a shift in direction, rising steadily before demonetisation and falling sharply after. In Maharashtra and Rajasthan, female WPR was falling before the shock and continued to fall after demonetisation, though Maharashtra had an upward shift, while Rajasthan had a downward shift, in the falling trend line after the event.

\section{Regressions}

We corroborate the graphical evidence by regressing the workforce participation on its lagged value and a dummy variable for the demonetisation event. We construct one dummy variable called demo and include it in the regression. The variable demo is a dummy which takes value 1 from the month of November 2016, when demonetisation was announced, onwards. The regressions we run are of the following format, when we assume a break date of November 2016

$$
y_{t}=\alpha_{1 t}+\alpha_{2 t} * \text { demo }+\beta_{1 t} t+\beta_{2 t} t * \text { demo }+\gamma y_{t-1}+\epsilon_{t}
$$

where demo is a dummy variable taking the value 1 after November 2016, $\beta_{1 t} t$ indicate the lag of WPR ${ }^{2}$ for overall, male and female (LWPR, LWPRM, LWPRF), The coefficient $\alpha_{2 t}$ indicates if the demonetisation even caused a change in the intercept, whereas $\beta_{2 t}$ coefficient for demo*time (demotime) indicates if the demonetisation even caused a change in the slope of the deterministic time trend. Demotime is the variable of interest to us, which

$\overline{2}$ We also tried out more than one time point lag in WPR, but the results were no promising. 


\section{(a) Gujarat:}
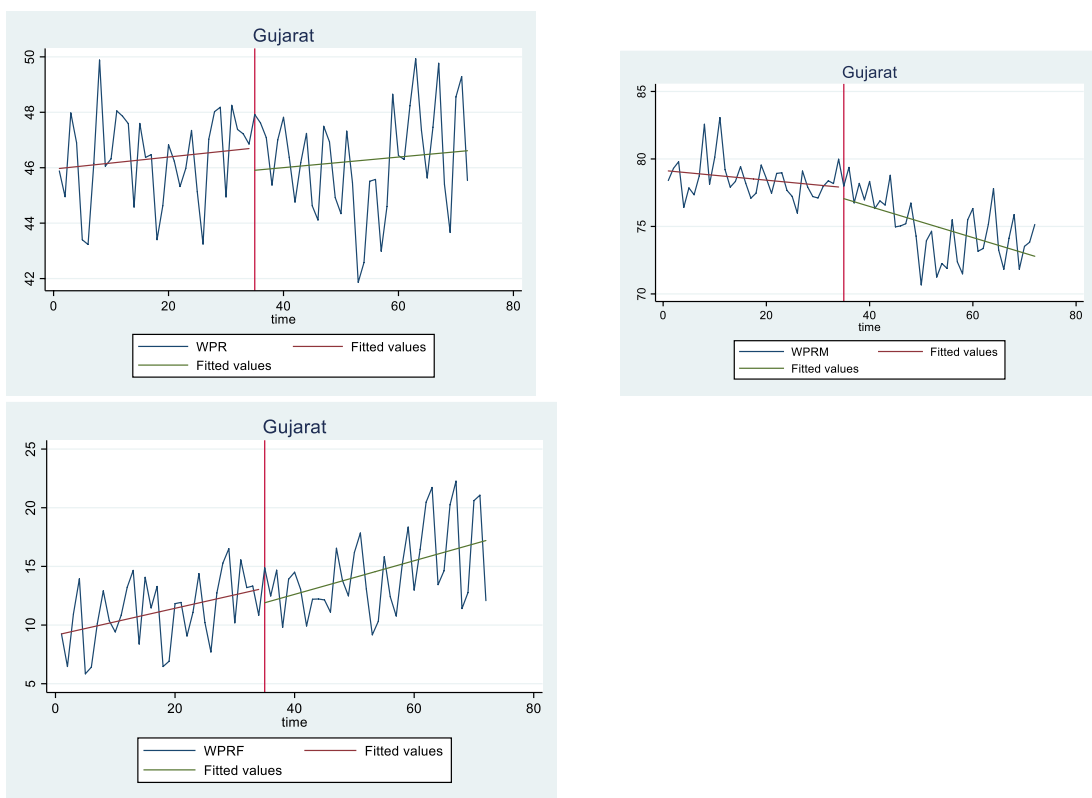

(b) Maharashtra:
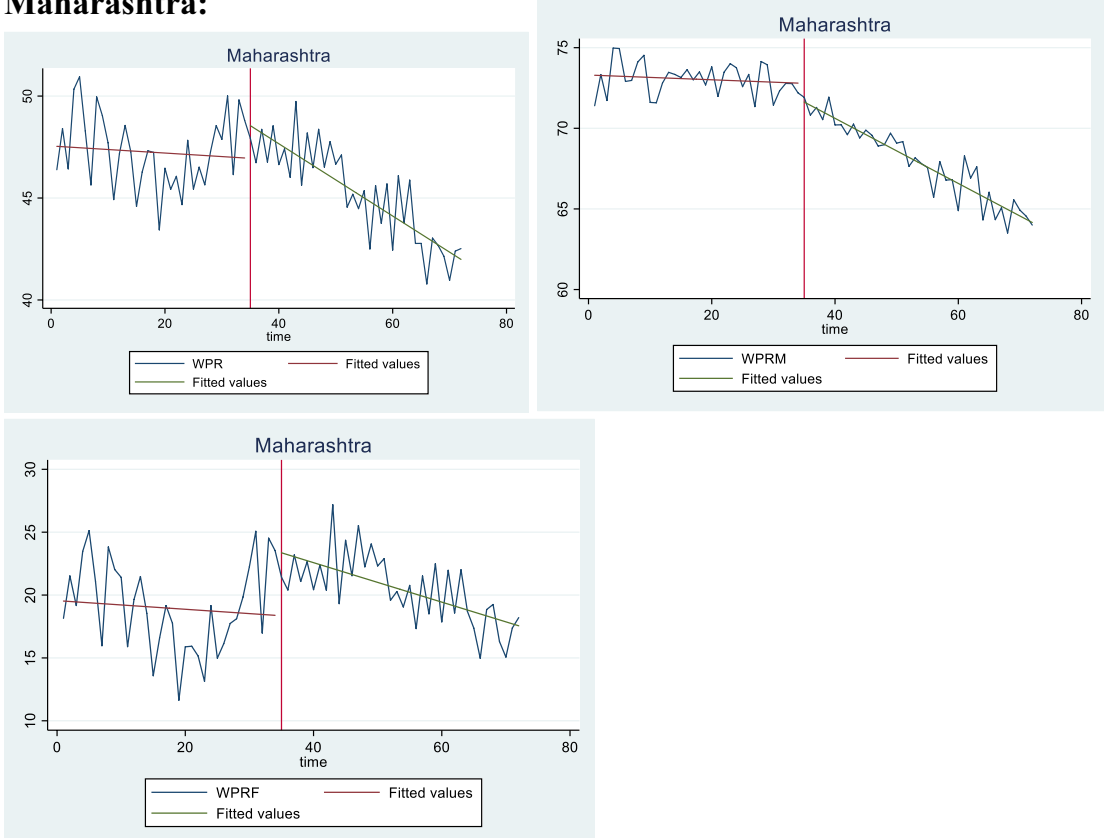

Figure 1 Workforce participation rates for all WPR, male WPR and female WPR for a Gujarat, b Maharashtra, c Madhya Pradesh, d Chhattisgarh and e Rajasthan 
( c) Madhya Pradesh:
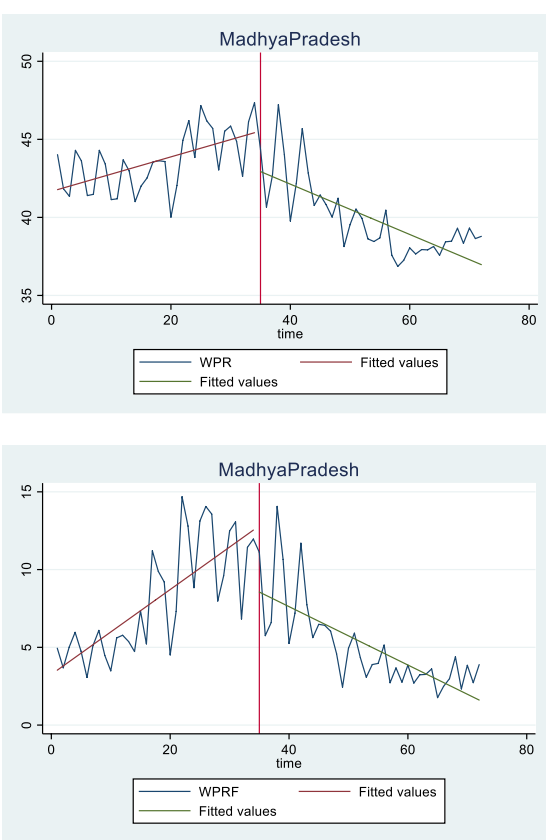

(d) Chhattisgarh:
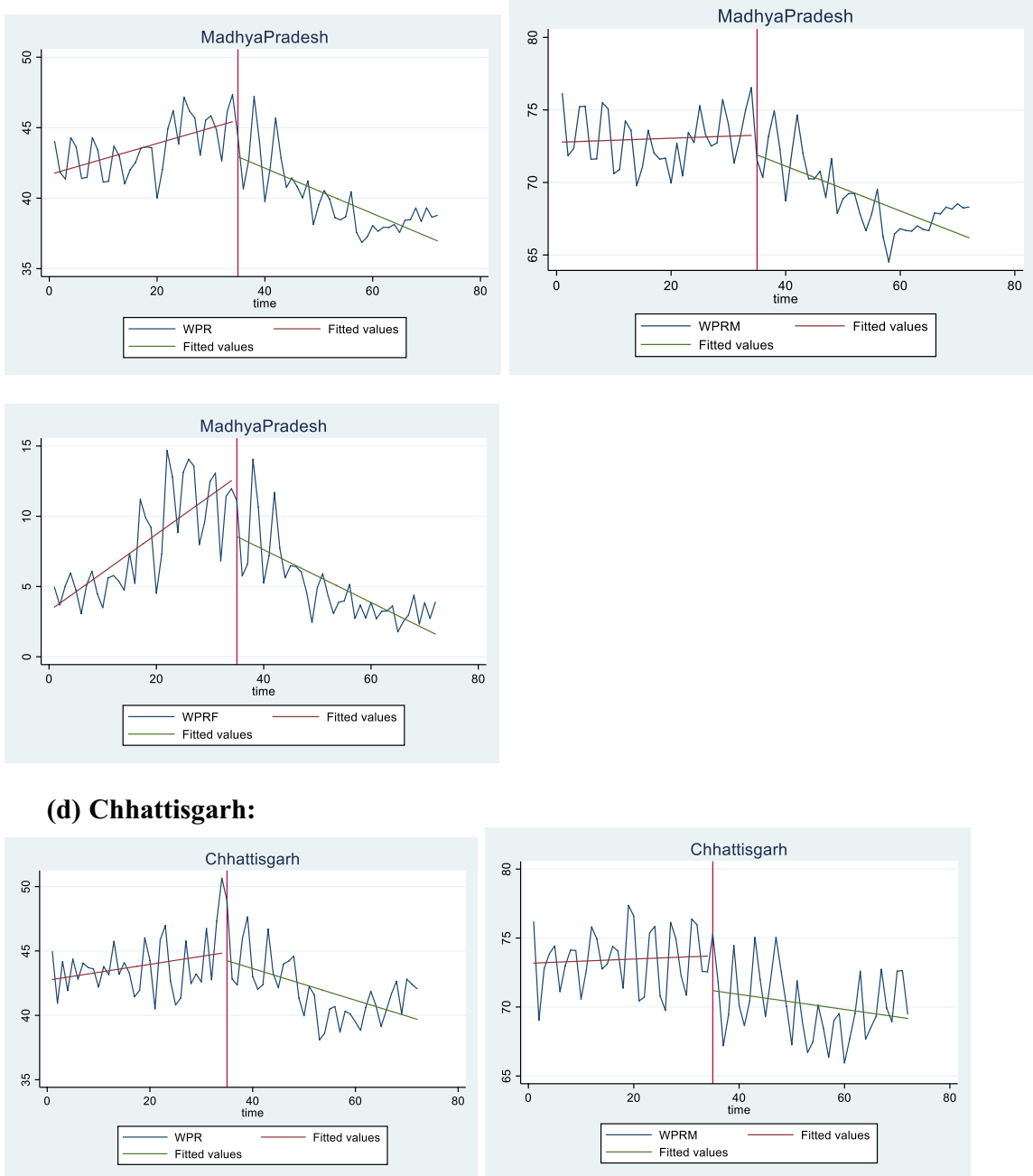

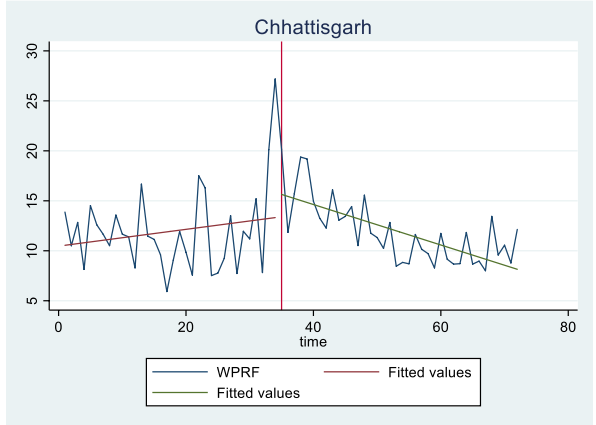

Figure 1 (continued) 


\section{(e) Rajasthan}
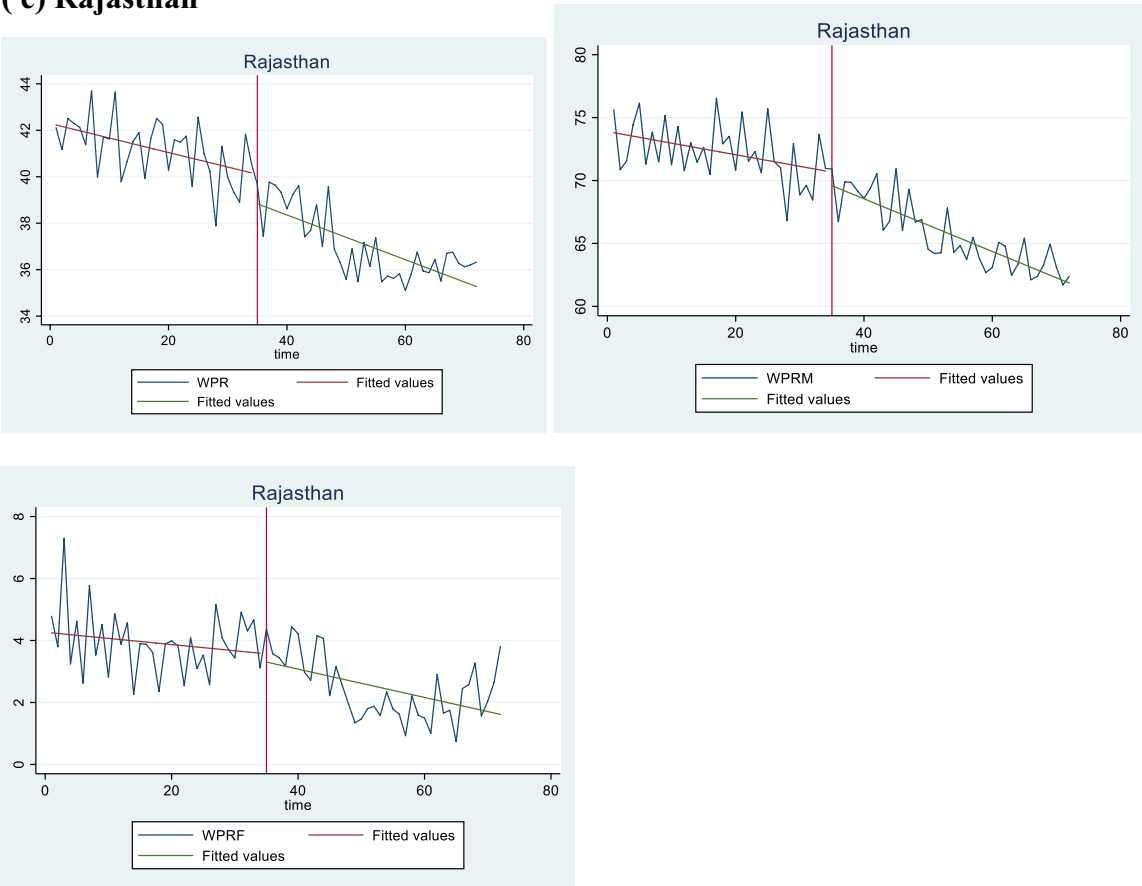

Figure 1 (continued)

Table 1 Regression results for total, male, female WPR growth rates, Gujarat, January 2014 to December 2019

\begin{tabular}{llll}
\hline Variables & WPR & WPR M & WPR F \\
\hline L.WPR & 0.234 & & \\
L.WPRM & $(1.96)$ & & \\
& & 0.231 & \\
L.WPRF & & $(1.91)$ & 0.0444 \\
Time & & & $(0.35)$ \\
& 0.0164 & -0.0291 & 0.109 \\
Demo & $(0.5)$ & $(-0.92)$ & $(1.89)$ \\
& -0.556 & 1.153 & -2.096 \\
Demotime & $(-0.35)$ & $(0.74)$ & $(-0.77)$ \\
& -0.00196 & -0.0547 & 0.0266 \\
ccons & $(-0.05)$ & $(-1.32)$ & $(0.37)$ \\
& $35.20 * * *$ & $60.89 * * *$ & $8.738^{* * *}$ \\
R-squared & $(6.35)$ & $(6.33)$ & $(5.49)$ \\
F-statistics & 0.068 & 0.6133 & 0.354 \\
N & 1.2 & 26.16 & 9.04 \\
& 71 & 71 & 71 \\
\hline
\end{tabular}

Robust standard errors in parentheses; *** $p<0.01$, ** $p<0.05$, $* p<0.1$ 
Table 2 Regression results for total, male, female WPR growth rates, Maharashtra, January 2014 to December 2019

\begin{tabular}{|c|c|c|c|}
\hline Variables & WPR & WPR M & WPR F \\
\hline L. WPR & $\begin{array}{l}0.00965 \\
(0.08)\end{array}$ & & \\
\hline L. WPR M & & $\begin{array}{l}-0.151 \\
(-1.28)\end{array}$ & \\
\hline L.1 WPR F & & & $\begin{array}{l}0.219 \\
(1.78)\end{array}$ \\
\hline Time & $\begin{array}{l}-0.0236 \\
(-0.81)\end{array}$ & $\begin{array}{l}-0.0272 \\
(-1.68)\end{array}$ & $\begin{array}{l}-0.0283 \\
(-0.53)\end{array}$ \\
\hline Demo & $\begin{array}{l}6.978 * * * \\
(4.16)\end{array}$ & $\begin{array}{l}5.995 * * * \\
(5.82)\end{array}$ & $\begin{array}{l}7.103^{*} \\
(2.53)\end{array}$ \\
\hline Demotime & $\begin{array}{l}-0.152^{* * * *} \\
(-3.64)\end{array}$ & $\begin{array}{l}-0.205^{* * * *} \\
(-6.70)\end{array}$ & $\begin{array}{l}-0.0937 \\
(-1.36)\end{array}$ \\
\hline _cons & $\begin{array}{l}47.24 * * * \\
(7.94)\end{array}$ & $\begin{array}{l}84.60 * * * \\
(9.82)\end{array}$ & $\begin{array}{l}15.37 * * * \\
(5.72)\end{array}$ \\
\hline $\mathrm{N}$ & 71 & 71 & 71 \\
\hline R-squared & 0.5669 & 0.9284 & 0.2485 \\
\hline F-statistic & 21.59 & 214.06 & 5.46 \\
\hline
\end{tabular}

Robust standard errors in parentheses; *** $p<0.01$, ** $p<0.05$, $* p<0.1$

will tell us whether the macro-shock of demonetisation had an impact on employment in the state and the direction of change.

In the trendline break graphs for Gujarat, we saw that there was no change in direction before or after demonetisation shock (Fig. 1). WPR trend line rose for overall and female and fell for men before and after the shock. The regression results with the dummies for demotime did not show a significant result, for overall, men or women's WPR (Table 1). It appears that demonetisation did not have a significant impact on employment in Gujarat, or the population was able to adjust quickly to the shock. Women's participation in Gujarat appeared to increase counter to the all India trend discussed earlier without any significant impact of the macro-shock of demonetisation. Men's participation, however, declined though this also was not significantly affected by the shock. The regression was able to explain about 60 percent of the variation in male WPR, but only about 35 percent of the variation in female WPR was indicated by the $\mathrm{R}$ squares. We will discuss these results later.

In Maharashtra, the pattern seen in the graphical presentations earlier is corroborated in the regression analysis for overall and men's WPR, showing significant negative impact of the demonetisation shock. More than 90 percent of the variation in male WPR is explained by this regression. But women's participation was not significantly affected by the shock of demonetisation (Table 2). In the trendline graphs (Fig. 1), we had noted a decline in female WPR before and after the shock, though there was a shift upward in the trendline after the shock. This meant that there was no sharp change in the trend to be captured by the more rigorous regression exercise, which shows an insignificant result and explains only 25 percent of the variation in female employment.

Madhya Pradesh and Chhattisgarh showed similar results where women's WPR rose before and declined after demonetisation (Fig. 1). In the regression, we found that the $\beta_{2 t}$ 
Table 3 Regression results for total, male, female WPR growth rates, Madhya Pradesh, January 2014 to December 2019

\begin{tabular}{llll}
\hline Variables & WPR & WPR M & WPR F \\
\hline L. WPR & $0.277^{*}$ & & \\
L. WPR M & $(2.43)$ & & \\
& & $0.278^{*}$ & \\
L. WPR F & & $(2.42)$ & \\
& & & 0.185 \\
Time & $0.0957^{* *}$ & 0.0344 & $(1.54)$ \\
& $(3.13)$ & $(1.11)$ & $0.230^{* * *}$ \\
Demo & $4.874 * *$ & $3.318^{*}$ & $(4.49)$ \\
& $(2.89)$ & $(2)$ & $9.540^{* * *}$ \\
Demotime & $-0.205^{* * *}$ & $-0.138^{* *}$ & $(3.81)$ \\
& $(-4.20)$ & $(-3.09)$ & $-0.379 * * *$ \\
cons & $29.84 * * *$ & $52.05 * * *$ & $2.524 * *$ \\
& $(6.25)$ & $(6.21)$ & $(2.9)$ \\
N & 71 & 71 & 71 \\
R-squared & 0.7204 & 0.6741 & 0.6556 \\
F-statistic & 42.51 & 34.14 & 31.41 \\
\hline
\end{tabular}

Robust standard errors in parentheses; $* * * p<0.01, * * p<0.05$, $* p<0.1$
Table 4 Regression results for total, male, female WPR growth rates, Chattishgarh, January 2014 to December 2019

\begin{tabular}{llll}
\hline & WPR & WPR M & WPR F \\
\hline L. WPR & $0.285^{*}$ & & \\
L. WPR M & $(2.39)$ & & \\
& & 0.116 & \\
L. WPR F & & $(0.96)$ & 0.22 \\
& & & $(1.69)$ \\
Time & & & 0.102 \\
& 0.0662 & 0.0299 & $(1.69)$ \\
Demo & $(1.78)$ & $(0.69)$ & $9.370^{*}$ \\
& 3.959 & 0.266 & $(2.65)$ \\
Demotime & $(1.97)$ & $(0.13)$ & $-0.246^{* *}$ \\
& $-0.144^{* *}$ & -0.0772 & $(-2.88)$ \\
_cons & $(-2.75)$ & $(-1.37)$ & $7.518^{* * *}$ \\
& $30.17 * * *$ & $64.32^{* * *}$ & $(3.9)$ \\
N & $(5.81)$ & $(7.26)$ & 71 \\
R-squared & 71 & 71 & 0.2585 \\
F-statistic & 0.3819 & 0.3529 & 5.75 \\
\hline
\end{tabular}

Notes: Robust standard errors in parentheses; $* * * p<0.01, * * p<0.05$, $* p<0.1$ 
Table 5 Regression results for total, male, female WPR growth rates, Rajasthan

\begin{tabular}{llll}
\hline Variables & WPR & WPR M & WPR F \\
\hline L. WPR & -0.02 & & \\
L. WPR M & $(-0.16)$ & $-0.238^{*}$ & \\
L. WPR F & & $(-2.01)$ & \\
& & & -0.00929 \\
Time & & $-0.104 * *$ & $(-0.07)$ \\
& $-0.0644 * *$ & $(-3.01)$ & -0.017 \\
Demo & $(-3.01)$ & $4.108 *$ & $(-0.95)$ \\
& -0.0896 & $(2.5)$ & 0.713 \\
Demotime & $(-0.09)$ & $-0.157 * * *$ & $(0.81)$ \\
& -0.034 & $(-3.52)$ & $(-0.0291$ \\
cons & $(-1.31)$ & $91.29 * * *$ & $4.236 * * *$ \\
& $43.15 * * *$ & $(10.4)$ & $(6.45)$ \\
N & $(8.29)$ & 71 & 71 \\
R-squared & 71 & 0.8209 & 0.4251 \\
F-statistic & 0.8197 & 75.62 & 12.20 \\
\hline Robust standard & errors in & & $* * 0.05$, \\
$* p<0.1$ & & &
\end{tabular}

coefficient for demotime was significantly negative for overall, male and female in both states (Tables 3 and 4). The impact of demonetisation was the strongest for women's WPR in both states as indicated by the $\beta_{2 t}$ coefficient in Madhya Pradesh and Chhattisgarh.

There was, however, one difference in the results of the two states. While in Madhya Pradesh more than 60 percent of the variation was explained by the concerned variables, in Chhattisgarh only about 25-35 percent of the variation in WPR was explained by the regression.

In Rajasthan, the trendline graphical presentation showed that overall, men and women's WPR fell consistently before and after the shock of demonetisation (Fig. 1). The regression for male WPR showed a significant negative impact of the shock, whereas overall and women's WPR were not significantly affected (Table 5). Here again variations in male WPR are better explained ( 82 percent) compared to female WPR (42 percent).

\section{Discussion of results}

In this paper, we compared the impact of the macroeconomic shock of demonetisation on employment in five Western states of India. In all states, the variation in employment of men is better explained by the regression results than that of female employment. Clearly, a lot of factors other than pure economic shocks affect female participation, and hence, these results are better suited to explain male participation. In Madhya Pradesh alone, nearly 65 percent of variation in women's WPR is explained by the macro shock.

Overall, the trendline structural break figures of the shock of demonetisation were corroborated by the regression results. Demonetisation had a significant negative impact on 
WPR of all workers in Maharashtra, Madhya Pradesh and Chhattisgarh and on male WPR in Maharashtra, Madhya Pradesh and Rajasthan. A significant negative impact of demonetisation on women's WPR was corroborated by the regression equations for Chhattisgarh and Madhya Pradesh.

Employment for all, males and females in Gujarat was not significantly affected by the shock of demonetisation. It appeared that workers in Gujarat were better able to negotiate the shock. Gujarat was fortunate to have two consecutive years of good monsoons in the years 2017-2018 and 2018-2019. Since our estimates are combined for rural and urban areas, it is possible that this could explain at least partly how Gujarat was better placed to negotiate the shock of demonetisation.

Chhattisgarh and Madhya Pradesh are the most backward states in Western India followed by Rajasthan. These states suffered a greater impact of demonetisation as the economic activity would be conducted almost fully in cash. These states have medium level of participation of women, which becomes essential for the survival of these households. With the shock of demonetisation, there was a fall in the women's WPR and men's WPR in Madhya Pradesh and women's WPR in Chhattisgarh. This would have further created a setback to the economic conditions of poor household in these states. Along with hastening the penetration of digital payment systems, financial inclusion will greatly benefit the growth of economic activity in these states.

Acknowledgement The authors acknowledge the able assistance by Sunaina Goel, Research Associate, Gender Center, Indian Institute of Management, Ahmedabad.

\section{References}

Chanda A (2019) Who Gained from India's Demonetization? Insights from Satellites and Surveys. Working Paper 06. LA: Louisiana State University

Chodorow-Reich G et al (2020) Cash and the economy: evidence from india's demonetization. Q J Econ 135(1):57-103

Guérin I, Lanos Y, Michiels S, Nordman CJ, Venkatasubramanian G (2017) Insights on demonetisation from rural Tamil Nadu: understanding social networks and social protection. Econ Polit Wkly 52(52):44-53

Gupta ND, Nandy D, Siddhanta S (2020) "Opt out” or kept out? The effect of stigma, structure, selection, and sector on the labor force participation of married women in India. Rev Dev Econ 00:1-22. https:// doi.org/10.1111/rode. 12672

Himanshu (2019) The seriousness of the problem of unemployment in India. Live Mint, 1 August

Hirway I, Shah A, Shah G (eds) (2014) Growth or development: which way is Gujarat going? Oxford University Press, Delhi

IDF (2017) Reassessing the Impact of Demonetisation on Agriculture and Informal Sector, RACE, January. https://www.idfresearch.org/uploads/R_a_c_e/1546941125_7201701304321.pdf. Accessed 25 May 2020.

Kannan KP, Raveendran G (2019a) Jobless growth becomes more systemic. The Hindu, 12 July

Kannan KP, Raveendran G (2019b) From jobless to job-loss growth gainers and losers during 2012-18. Econ Polit Wkly 54(44):38-44

Karmakar S, Narayanan A (2019b) Do households care about cash? Exploring the heterogeneous effects of India's demonetization, REM Working Paper 073-2019. Portugal.

Kim A, Voos P (2007) The korean crisis and working women. J Contemp Asia 37(2):190-208

Lim JY (2000) The effects of the east asian crisis on the employment of women and men: the philippine case. World Dev 28(7):1285-1306

Mehrotra S, Sinha S (2017) Explaining falling female employment during a high growth period. Econ Polit Wkly 52(39):54-62

Smith JP, Thomas D, Frankenberg E, Beegle K, Teruel G (2002) Wages, employment and economic shocks: evidence from Indonesia. J Popul Econ 15(1):161-193 
Sood A (2012) Poverty amidst prosperity: essays on the trajectory of development in Gujarat. Aakar Books, Delhi

Unni J, Naik R (2014) Gujarat's employment story: growth with informality’ in Indira Hirway. In: Shah A, Shah G (eds) Growth or development: which way is Gujarat going? Oxford University Press, India, Delhi, pp 270-299

Unni J (2020) Boosting women's work participation. In: Mehrotra S (ed) Reviving jobs: an agenda for growth. Delhi, Penguin Random House

Publisher's Note Springer Nature remains neutral with regard to jurisdictional claims in published maps and institutional affiliations. 